\title{
Desempenho Exportador e Aprimoramento Tecnológico da China em comparação com Japão e Dragões Asiáticos nos anos 2000
}

\section{Export Performance and Technological Improvement of China in comparison with Japan and Asian Dragons in the years 2000}

\author{
Maria Inês Cunha Miranda* \\ Clésio Lourenço Xavier** \\ Ana Paula Macedo de Avellar***
}

\begin{abstract}
Resumo: As exportações chinesas vêm incorporando maior conteúdo tecnológico, sofisticando sua produção, o que permite a ampliação de seu market-share nos mercados americano e europeu. Diante disso, o objetivo do artigo é analisar a incorporação de produtos sofisticados na pauta exportadora chinesa durante os anos 2000 vis-à-vis seus parceiros asiáticos, tais como Japão, Cingapura, Coreia do Sul e Hong Kong, os quais obtiveram sucesso no processo de upgrading tecnológico. Baseando-se nos dados do United Nations Commodity Trade Statistics Database, apresenta-se a decomposição da pauta exportadora segundo intensidade tecnológica. O principal resultado auferido é de que apesar do intenso esforço dedicado pela economia chinesa para a incorporação de produtos mais sofisticados, a China ainda encontra-se afastada do padrão considerado "ideal", aqui visto como a economia japonesa.
\end{abstract}

Palavras-chave: Comércio internacional, Intensidade tecnológica, Países asiáticos.

Abstract: The Chinese exportations are incorporating higher-tech, sophisticated production, allowing the expansion of its market-share in the U.S and European market. Therefore, the goal is to analyze the real incorporation of sophisticated products in the Chinese exporting agenda during the 2000s vis-à-vis its Asian partners such as Japan, Singapore, South Korea and Hong Kong- countries that had success in the technological upgrading process. For this purpose, this article based on data from United Nations Commodity Trade Statistics Database presents the analysis of exporting agenda according to technological intensity of studied countries. The main result earned is that despite the intense effort devoted by the Chinese economy for the incorporation of technologically sophisticated products, China stills far from the standard "ideal", here seen as the Japanese economy.

* Doutoranda em Economia no Instituto de Economia da Universidade Federal de Uberlândia (UFU).E-mail: mcunhamiranda@yahoo.com.br

** Professor doutor do Instituto de Economia da Universidade Federal de Uberlândia (UFU). Pesquisador e bolsista de Produtividade do CNPq. E-mail: clesio@ie.ufu.br

*** Professora doutora do Instituto de Economia da Universidade Federal de Uberlândia (UFU). Pesquisadora bolsista de Produtividade do CNPq e pesquisadora da Fapemig. E-mail: anaavellar@ ie.ufu.br 
Keywords: Trade international, Technological intensity, Asian countries.

JEL Classification: O30; F14; F50; O53; O57.

\section{Introdução}

Os últimos 25 anos do século XX foram cenário da rápida emergência dos países asiáticos, dentre eles, destacam-se o Japão e, posteriormente, Cingapura, Coreia do Sul, Hong Kong e Taiwan, denominados como Dragões Asiáticos (GAULIER; LEMOINE; ÜNAL-KESENCI, 2006). Esses países são conhecidos pelo seu rápido processo de industrialização e incorporação de setores intensivos em tecnologia, conformando na região asiática uma estrutura de outsourcing configurada para atender o mercado exportador.

A partir de 1980 também surge um importante player na região asiática que atualmente se destaca no cenário mundial: a China. $\mathrm{O}$ crescimento chinês se baseou na expansão industrial, em especial de produtos de baixo valor agregado voltados para a exportação em massa. Com a ascensão da economia chinesa, o desenho regional asiático vem se transformando, permitindo à China ocupar relevante papel na região, tomando a posição de líder, antes exercida pelo Japão, na configuração do outsourcing regional.

Diante disso, cabe destacar o acelerado crescimento dessas economias baseado principalmente na elevação de suas participações no comércio internacional, conformando-se uma importante plataforma exportadora mundial. Assim sendo, destaca-se especialmente a relevância da participação de setores intensivos em tecnologia na pauta exportadora desses países como "motor" do acelerado crescimento dos países da região. Apesar da queda de participação dos produtos manufaturados asiáticos no comércio internacional, a região se torna relevante dado o crescente superávit que detém com o resto do mundo.

Diante da importância desses países no âmbito do comércio mundial, em especial nos setores intensivos em tecnologia, o presente artigo analisará o desempenho das exportações asiáticas no que se refere à incorporação de conteúdo tecnológico durante a década de 2000. Nesse sentido, o trabalho visa responder à questão de qual é o desempenho das exportações baseadas em alta tecnologia da China vis-à-vis as economias da região que já se destacam por seu upgrading tecnológico, tais como Cingapura, Coreia do Sul, Hong Kong e Japão. A principal hipótese que guia este trabalho é a de que apesar dos esforços recentes da economia chinesa rumo à incorporação de capacitações tecnológicas, seu desempenho nos setores de alta tecnologia ainda é inferior em comparação com os países analisados.

Portanto, buscar-se-á analisar o desempenho das exportações chinesas vis-à-vis seus vizinhos asiáticos, a fim de verificar se ocorreu uma mudança na compo- 
sição setorial rumo à incorporação de setores intensivos em tecnologia. Para tanto, este artigo encontra-se organizado em cinco seções, além desta breve introdução. A segunda seção apresenta a importância da modificação da estrutura de exportação rumo à incorporação de conteúdo tecnológico e como isso afeta o desempenho dos países em desenvolvimento. A terceira seção, por sua vez, descreve a metodologia do trabalho. Na sequência, a quarta apresenta os indicadores da pauta exportadora dos países analisados. E, finalmente, a quinta seção se dedica à construção de um índice de intensidade tecnológica, o qual é construído por meio da intensidade tecnológica média das exportações desses países, tal como desenvolvido por Nonnemberg (2011) e seus principais resultados. Por fim, apresentam-se as considerações finais.

\section{Estrutura Tecnológica e Exportação}

Na recente economia do conhecimento, a inovação é vista como principal elemento competitivo. O processo de incorporação de inovação possibilita aos países avançar na produção de produtos manufaturados intensivos em tecnologia e, assim, ampliar seus market-shares. Corroborando essa visão, o trabalho da Conferência das Nações Unidas para o Comércio e o Desenvolvimento (2004, p. 3) menciona que, para "[...] gerar e obter tais ganhos [de desenvolvimento], e desse modo usar o comércio como uma verdadeira locomotiva de crescimento e desenvolvimento, é [necessário] promover uma participação maior e benéfica dos países em desenvolvimento nos setores novos e dinâmicos do comércio mundial".

Nos países desenvolvidos, a inovação advém, majoritariamente, da geração de conhecimentos internos, devido ao desenvolvimento de seus sistemas nacionais de inovação, os quais "[...] realizam esforços de pesquisa e desenvolvimento (P\&D), incorporando esse conhecimento aos seus produtos, elevando sua competitividade" (NONNEMBERG, 2011, p. 9). Ao contrário dos países em desenvolvimento ou de industrialização atrasada, a inovação é resultado em grande medida da transferência internacional de tecnologia, acompanhada da geração doméstica de capacidades de absorver e desenvolver tais tecnologias, o que segundo Nonnemberg (2011) reduz o custo de incorporação e estimula o investimento em setores intensivos em tecnologia.

Diante disso, Lall (2000a) aponta que, segundo a teoria padrão de comércio internacional, a estrutura de exportações era meramente acidental, não há diferenciação entre a especialização em produtos de baixa tecnologia ou naqueles intensivos em tecnologia, ou seja, a composição setorial não tem qualquer relevância. Diante disso, os países em desenvolvimento deveriam se especializar na exportação de produtos baseados em recursos naturais ou intensivos em trabalho, com baixas exigências de habilidades e de atividades tecnológicas. Baseado nisso, 
o país evoluiria ao incorporar setores mais intensivos em capital, habilidades ou atividades intensivas em tecnologia como mera resposta à modificação de suas dotações iniciais. Dessa forma, percebe-se que os países em desenvolvimento seriam apenas importadores de tecnologia dos países desenvolvidos, utilizando-a passivamente, sendo vistos como "techonological followers".

Dessa forma, segundo Lall (2000b), os mercados internacionais de tecnologia são tomados como sendo os mais eficientes, no sentido do que as firmas nos países em desenvolvimento podem achar, selecionar, comprar e transferir tecnologias sem incorrerem em custos adicionais. Além disso, essas empresas também podem utilizar essas tecnologias sem também gerarem custos adicionais, dado que seus processos produtivos são facilmente moldáveis.

Contudo, o referido autor aponta que esse tipo de visão não é coerente com a realidade, tendo em vista que depende somente da estrutura interna de fatores, uma vez que cada país detém uma estrutura de exportação diferente. Dessa forma, tomando como referência a abordagem da capacidade (capability aproach), ${ }^{1}$ a estrutura de exportação é path dependence e cumulativa, com grandes dificuldades para ser modificada no curto prazo. A estrutura de exportação é produto da acumulação interna de capacitações, desenvolvida por meio do processo de aprendizado incremental. Contudo, cabe destacar que não é rígida, podendo ser modificada como respostas a sinais de mercado, novas tecnologias, entre outras; entretanto, essa estrutura leva tempo e esforços significativos para ser modificada.

Ainda segundo essa abordagem, as firmas nos países em desenvolvimento operam com conhecimento imperfeito acerca das alternativas tecnológicas, sendo, dessa forma, o processo de procura de tecnologias alternativas, sem dúvida, custoso. Assim, uma vez que essa tecnologia é importada, para que seja eficientemente utilizada, deverá se criar habilidades internas e conhecimento prévio. Assim, a abordagem da capacidade sugere que as vantagens comparativas dependem das habilidades internas de usar eficazmente a nova tecnologia e não da dotação de fatores.

Outro trabalho que destaca a relevância das capacidades internas de absorção de conhecimento tecnológico é o trabalho de Cohen e Levinthal (1989). Segundo esses autores, os economistas ligavam o processo de P\&D com a geração de um produto: a nova informação. Contudo, os desenvolvimentos em P\&D não geram somente novas informações, mas também criam habilidades internas à firma para assimilar e explorar novas informações (COHEN; LEVINTHAL, 1989), pois a capacidade de absorção da firma depende de uma série de fatores, relacionados às características das firmas, tais como "[...] habilidades individuais de seus

1 Para um maior aprofundamento da evolução da abordagem das capacitações tecnológicas, ver Figueiredo (2004). 
funcionários, a sua forma de organização interna e de seus investimentos prévios de Pesquisa e Desenvolvimento" (DE NEGRI, 2006, p. 2).

Dessa forma, os autores sugerem que as atividades de P\&D contribuem para o processo de aprendizado interno à firma e, com isso, conduzem a dois resultados: a) reforçar a capacidade de gerar inovações; e b) absorver novos conhecimentos tecnológicos externos. Assim sendo, segundo De Negri (2006, p. 2), a “[...] capacidade de absorção ou de aprendizado é um dos elementos fundamentais para o desempenho tecnológico das firmas e para que elas possam se apropriar de eventuais transbordamentos de tecnologias das mais diversas fontes". Por esse motivo, as firmas que possuem altos níveis de capacidade de absorção tendem a ser mais proativas e exploram oportunidades dadas pelo ambiente em que estão inseridas, independente de seu desempenho corrente, enquanto as firmas que possuem modestas capacidades de absorção tendem a ser reativas, procurando alternativas somente como resposta a falhas em algum critério de desempenho (COHEN; LEVINTHAL, 1989).

Tendo isso em vista a modificação de uma pauta exportadora intensiva em recursos naturais para uma pauta sofisticada e baseada em manufaturas com altos índices de intensidade tecnológica, faz-se necessário um conjunto integrado de políticas industriais ativas, conforme aponta a experiência dos países em desenvolvimento:

[...] a necessidade de uma abordagem política focada dentro da estrutura geral do desenvolvimento, que construa e sustente os fatores chaves estratégicos e as ligações entre eles, incluindo a capacidade da oferta, a produtividade, a competitividade e a dotação tecnológica; os investimentos doméstico e estrangeiro; a entrada e o acesso ao mercado; as preferências e as demandas mutantes; a divisão regional do trabalho, dentre outros (CONFERÊNCIA DAS NAÇÕES UNIDAS PARA O COMÉRCIO E O DESENVOLVIMENTO, 2004, p. 3).

Diante disso, a importância da incorporação de setores intensivos em tecnologia tem sido analisada por vários trabalhos, ainda insuficiente no que se refere aos países em desenvolvimento. A maioria dos estudos que se dedicam à análise os países desenvolvidos aponta que o esforço inovativo mensurado pelos gastos em P\&D impacta positivamente o comportamento exportador, relação essa não linear nas economias em desenvolvimento. ${ }^{2}$

Nesse sentido, faz-se necessário analisar alguns dos trabalhos que se dedicam a estudar os países em desenvolvimento e suas especificidades. ${ }^{3}$ Dentre eles,

2 Isto se deve em grande medida às características locais e ao desenvolvimento prévio de habilidades.

3 Cabe salientar que não é escopo deste trabalho esgotar esse assunto, mas apenas apontar alguns estudos que se dedicam aos países em desenvolvimento. 
destaca-se o trabalho de Kumar e Siddharthan (1994), no qual os autores analisam as variações do comportamento exportador das firmas indianas em 13 setores da indústria, cerca de 640 empresas, usando o modelo Tobit para o período de 1988 a 1990. Segundo os resultados obtidos pelo modelo, os gastos em $P \& D$ são significativos para explicar o comportamento exportador, corroborando a hipótese de que, em países em desenvolvimento como a Índia, as atividades das firmas inovativas contribuem para a competitividade das exportações nos setores de média e baixa tecnologia. Isso porque nos setores de alta tecnologia, de acordo com os autores, as firmas dos países em desenvolvimento precisam desenvolver capacitações que vão além das atividades de P\&D.

Outro estudo relevante é de Wignajara (2011), o qual se dedica a estudar a relação entre a composição de propriedade de capital, inovação e exportação nas firmas dos setores de eletrônica e automotivo na China, utilizando do modelo Probit. O principal resultado da pesquisa é de que as empresas exportadoras que apresentam altos níveis de inovação e aprendizado são, em sua maioria, de propriedade estrangeira e também são geralmente maiores do que as firmas não exportadoras.

Para o Brasil, também se encontram trabalhos empíricos que levantam a relevância da inovação tecnológica para o comportamento exportador das firmas brasileiras. Dentre eles, destaca-se o trabalho de De Negri (2005), o qual tem como objetivo analisar a relação entre os padrões tecnológicos e o desempenho externo das firmas brasileiras. A autora aponta que a tecnologia desempenha papel relevante nas exportações das firmas brasileiras, sendo que as firmas inovadoras em produto exportam mais vis-à-vis do que as empresas não inovadoras. Para produtos de baixa tecnologia, não é relevante se a firma é ou não inovadora, não apresentando positivo impacto para o desempenho exportador. Já no que se refere aos setores intensivos em tecnologia o fator mais relevante para a competitividade das exportações é, sem dúvida, as inovações de processo. Contudo, isso não significa que essas firmas não façam inovação de produto, ao contrário, as firmas desenvolvem novos produtos, mas seus esforços encontram-se voltados para a adaptação de produtos estrangeiros para o mercado interno.

O trabalho de Arbix, Salerno e De Negri (2005), o qual se dedica a analisar a relação entre internacionalização e seu impacto sobre as exportações, também aponta a incorporação de setores tecnologicamente intensivos como importante fator para a internacionalização das empresas brasileiras. As empresas que se internacionalizam com foco na inovação tecnológica, em geral, pagam melhores salários, são maiores, empregam mão de obra mais qualificada, então, oferecem empregos com maior qualidade e exportam produtos com maior valor agregado. Portanto, a inovação tecnológica afeta positivamente a competitividade das 
firmas, sendo um importante fator para a internacionalização das empresas, via investimento direto.

Dessa forma, faz-se necessária uma análise detalhada da pauta exportadora dos países selecionados, com o fim de verificar qual o desempenho dos setores intensivos em tecnologia durante a década de 2000 . O procedimento metodológico para a adequada desagregação das exportações será exposto na próxima seção.

\section{Procedimentos Metodológicos}

O dinamismo no comércio mundial na atualidade tem sido conferido ao fluxo intenso de produtos intensivos em tecnologia. Tendo isso em vista, um bom método para corroborar essa hipótese é, sem dúvida, desagregar as exportações de acordo com a intensidade tecnológica, o que permite qualificar as exportações de cada país. Contudo, esse esforço não se dá sem ambiguidades, dado que existem várias metodologias de classificação das exportações.

A discussão em torno das metodologias de desagregação das exportações aponta que, por meio delas, torna-se complexa a captura dos elementos que proporcionam o upgrading tecnológico, não permitindo a distinção entre os níveis tecnológico das atividades e seus possíveis melhoramentos. Dessa forma, é difícil auferir o conteúdo tecnológico das exportações, dado que não se absorve os aspectos intrínsecos àquelas atividades, agregando atividades com diferentes conteúdos tecnológicos em uma mesma categoria de produtos. Ademais, essas classificações não conseguem demonstrar o processo envolvido na produção do mesmo produto em diferentes regiões, muito menos se há distinção entre inovação de produto e de processo.

Tendo em vista essa discussão, o presente trabalho opta pelo critério de desagregação conforme a tipologia de Lall (2000a). O trabalho de Lall (2000a), que desenvolve uma classificação setorial das exportações, baseia-se em cinco grupos: produtos primários, manufaturas baseadas em recursos, baixa tecnologia, média tecnologia e alta tecnologia.

No grupo dos produtos primários, incluem-se todos aqueles produtos brutos e gêneros alimentícios em geral, tais como fruta, carne, café, chás em geral, petróleo cru, gás, entre outros. Nesse grupo, enquadram-se os produtos que necessitam relativamente de poucas vantagens comparativas. Já nas manufaturas baseadas em recursos, incluem-se aqueles setores intensivos em trabalho e/ou setores de processamento de alimentos, sendo segmentos que seus processos produtivos são intensivos em capital, escala e habilidades tecnológicas, sendo que as vantagens comparativas desses produtos são fruto da disponibilidade local de recursos (naturais e trabalho). 
Nas manufaturas de baixa tecnologia, enquadram-se aqueles produtos baseados em tecnologias simples e já amplamente difundidas, as quais são primeiramente corporificadas nos bens de capital, com baixos gastos de $\mathrm{P} \& \mathrm{D}$ e requerem poucas habilidades, sendo em geral produtos padronizados. As barreiras à entrada são relativamente baixas e os custos de trabalho são os responsáveis pela maior parte dos custos. O crescimento do mercado desses produtos tende a ser lento, com baixa elasticidade renda (aproximadamente igual a 1 ).

No grupo das manufaturas de média tecnologia, encontram-se os produtos que têm tecnologias complexas, com níveis moderados de gastos em $\mathrm{P} \& \mathrm{D}$, habilidades avançadas e longos períodos de aprendizado, e, por isso, as barreiras à entrada tendem a ser altas nesses setores. Nesse grupo, compreende-se a maior parte das habilidades e escala-intensiva dos bens de capital e produtos intermediários, sendo ele, portanto, considerado o "coração" da atividade industrial das economias maduras.

Já no que se refere às manufaturas de alta tecnologia, esses produtos são baseados em avançadas tecnologias e rapidamente mutáveis, com altos investimentos em P\&D com ênfase no design dos produtos; esses tipos de produto requerem sofisticadas infraestruturas tecnológicas, altos níveis de especialização e interação frequente entre as empresas e entre as firmas e institutos de pesquisa.

Contudo, independente do aprimoramento das classificações de comércio internacional, ainda apresentam o problema de "ilusão estatística", segundo Markwald (2004), dada certa dose de arbitrariedade na classificação da pauta exportadora. Diante disso, o presente trabalho opta pela adoção da tipologia apresentada por Lall (2000a). Essa classificação será efetuada a partir da agregação dos dados da pauta exportadora dos países analisados do Standard International Trade Classification (SITC) (três dígitos) da revisão 3, adotada pelas Organização das Nações Unidas. Com base nessa metodologia, parte-se para a análise da composição das exportações dos países analisados segundo a intensidade tecnológica, sendo os principais resultados apresentados na próxima seção.

\section{Composição das Exportações segundo Intensidade Tecnológica}

Como visto, o conteúdo tecnológico é extremamente relevante para o crescimento das exportações, especialmente o crescimento das exportações de alta tecnologia dos países em desenvolvimento, "[...] reflexos da interação entre a realocação de simples processos de alta tecnologia com o rápido crescimento de mercados guiados pela inovação e pela nova demanda" (LALL, 2000b, p. 12). Nesse sentido, como já apontado, não se trata apenas de alteração de produtividade, a qual é substancial entre os produtos de alta tecnologia, mas de apontar que os produtos de maior conteúdo tecnológico têm capacidade de induzir o crescimento 
do montante exportado, assim como a elevação do Produto Interno Bruto (PIB) induzido pelo dinamismo do comércio exterior. ${ }^{4}$

Assim, as relações no continente asiático vêm sendo dinamizadas, devido à elevação do market-share das exportações dos países da região, liderada pela economia chinesa. Diante disso, observa-se, no Gráfico 1, a evolução da taxa de crescimento das exportações dos países asiáticos durante a década de 2000.

Gráfico 1 - Evolução da taxa de crescimento das exportações dos países selecionados durante a década de 2000 (em \%)

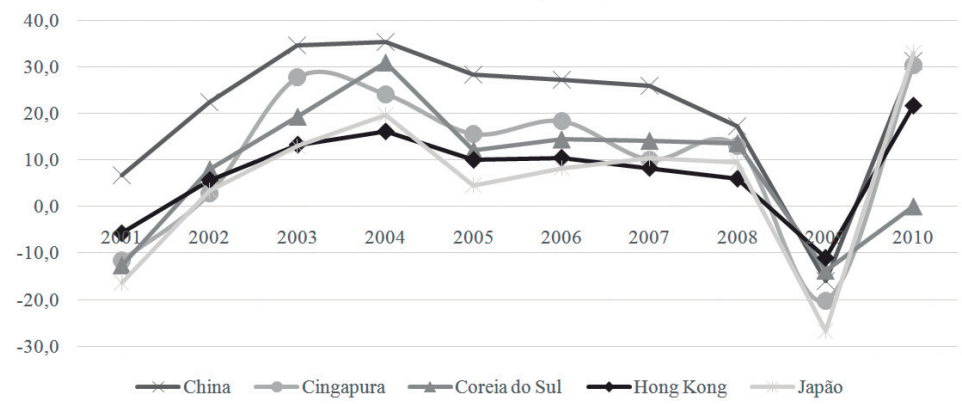

Fonte: Elaboração própria a partir de dados da United Nations Commodity Trade Statistics Database (2011).

Segundo o Gráfico 1, pode-se constatar que a taxa média de crescimento das exportações totais dos países asiáticos analisados em seu conjunto ficou em torno de $11 \%$ no subperíodo de 2000 a 2005, tendo caído para aproximadamente $10 \%$ no segundo subperíodo de 2006 a 2010. Isso se deve especialmente em função da queda das exportações mundiais devido à crise do subprime, tendo seus reflexos especialmente no ano de 2009, deprimindo as economias domésticas e retraindo a demanda interna, o que leva a uma queda do montante exportado de todas as economias, como pode ser visto no Gráfico 1. Como pode ser percebido, o país que apresentou a maior taxa de crescimento das exportações nos dois subperíodos analisados foi, sem dúvida, a China, tendo sua maior taxa de crescimento em 2004, atingindo cerca de $35 \%$ ao ano.

Depois da China, destaca-se o crescimento das exportações da Coreia do Sul, seguido por Cingapura e, por fim, Japão. A economia japonesa vem perdendo participação após a ascensão chinesa, especialmente depois da década de 1990. Em 1995, a moeda do Japão, o Yen, sofreu uma desvalorização de cerca de 30\%

$4 \quad$ Cabe destacar que aqui se exclui a análise do papel da demanda internacional, a qual também exerce papel relevante para a determinação do montante exportado; no entanto, sabe-se que a demanda internacional atualmente vem crescendo nos setores de alta tecnologia, mas também de produtos agrícolas, liderada especialmente pela China ("Efeito China"). Nesse sentido, destaca-se a significativa influência exercida pela demanda internacional na determinação dos fluxos comerciais. 
em relação ao dólar, o que implicou a valorização da cesta de moedas asiáticas que se encontravam atreladas ao Yen. Enquanto isso, a moeda chinesa, que não continha nenhuma paridade com o Yen, desvalorizou-se, deslocando a economia japonesa como principal parceiro comercial dos Estados Unidos, uma inflexão para as economias asiáticas (MEDEIROS, 2006).

Desde a Segunda Guerra Mundial, com a reconstrução japonesa coordenada pelos Estados Unidos, o Japão criou todo um aparato de desenvolvimento industrial intra-asiático, no qual este país exercia a liderança. Esse esquema, que recebeu a denominação de Gansos Voadores (EGV), foi desenvolvido primordialmente por Akamatsu (1962) para descrever o desenvolvimento industrial da economia japonesa, assim como as relações mantidas entre essa economia e seus vizinhos asiáticos, no processo de expansão do comércio intra-asiático.

De acordo com tal esquema, os países se especializavam conforme seus custos de produção, assim "[...] os países mais atrasados começam importando determinado produto, para posteriormente produzir para o mercado local e, numa fase seguinte, exportar" (MEDEIROS, 2011, p. 13). Assim, os custos de mão de obra crescentes em decorrência da absorção do excedente da força de trabalho são o elemento fundante do deslocamento das especializações. Em linhas gerais, esse esquema se assemelha aquele apresentado pela Teoria dos Hiatos Tecnológicos, na medida em que as barreiras à imitação vão se reduzindo, por meio da incorporação de conhecimento doméstico acerca do modus operandi da produção das mercadorias importadas.

A transferência produtiva asiática se deu de maneira hierarquizada e sequencial, segundo Leão (2011). As corporações japonesas, em um primeiro momento, se deslocaram para os países mais desenvolvidos da região que apresentavam alta capacidade exportadora, tais como Cingapura, Coreia do Sul, Taiwan e Hong Kong, conhecidos como Dragões asiáticos. Apesar da complexidade produtiva desses países, ainda apresentavam custos de trabalhos relativamente mais baixos que o Japão, além de apresentarem melhores condições de acesso ao mercado externo e políticas públicas voltadas para o esforço exportador concentrados nos setores de alta tecnologia. Dessa forma, "[...] o deslocamento da indústria japonesa foi resultado tanto da capacidade tecnológica e produtiva previamente acumulada por esses países, como pelo diferencial dos custos existentes" (LEÃO, 2011, p. 123).

Somente após a queda de participação da indústria japonesa e dos Dragões Asiáticos, os demais países da região menos desenvolvidos passaram absorver investimentos desses países voltados para a exportação, dentre eles, destacam-se a China e os Tigres Asiáticos (Filipinas, Indonésia, Malásia e Tailândia). O deslocamento para esses países se deu essencialmente em função do diferencial de custos, uma vez que o processo de industrialização desses países ainda não havia se completado, não existindo políticas industriais ativas no sentido de incorporar maior 
conteúdo tecnológico à sua indústria local. Contudo, o crescimento da economia chinesa impossibilitou que os Tigres Asiáticos crescessem puxados pelo comércio com a economia americana, dado que as importações americanas foram deslocadas para a China.

Ademais, a reação chinesa à crise asiática de 1997 foi a continuidade do crescimento interno por meio do programa público de obras e da manutenção da estabilidade de sua moeda indexada ao dólar em conjunto com políticas cambiais agressivas que permitiram a manutenção artificial da desvalorização da moeda chinesa, o que elevava sua competitividade. Por esse motivo, a manutenção do crescimento chinês implicou mudanças na dinâmica regional sem, contudo, desfazer o processo de triangulação comercial antes exercido pela economia japonesa. Dessa forma, a integração produtiva e a especialização vertical foi o principal processo que propiciou a expansão do comércio intra-asiático.

Além desses fatores, cabe destacar que os países asiáticos, por se moldarem nessa estrutura articulada, praticam políticas fortemente protecionistas com os países não participantes do grupo, impondo sérias restrições às importações relativas à "[...] preservação e controle do meio ambiente, à saúde e à segurança nacional são acionadas pelos países asiáticos de maneira abrangente e, em princípio, sem critérios específicos" (GUIMARÃES, 1999, p. 135), atuando como barreiras não tarifárias. Ademais, a estrutura de proteção desses países não é suficientemente transparente para os seus parceiros comerciais, além de também contar com vínculos transacionais fortes entre os países da região.

Nesse sentido, segundo Nonnemberg (2011), a partir dessa esquematização as exportações asiáticas cresceram a taxas sensivelmente mais elevadas, dado a maior participação de produtos intensivos em tecnologia na pauta exportadora desses países. Nesse sentido, tendo como propósito analisar em que medida a pauta exportadora chinesa vem incorporando conteúdo tecnológico vis-à-vis o Japão e os Dragões asiáticos, países esses que já apresentavam esforços no sentido de maior incorporação de conteúdo tecnológico, baseado na metodologia de Lall (2000a), destaca-se a evolução da composição da pauta exportadora dos países analisados durante o período da década de 2000, a qual se apresenta na Tabela 1. Para melhor compreensão dos dados, subdividiu-se a década de 2000 em dois quinquênios, utilizando média simples do crescimento do montante exportado pelas economias em análise. 
Tabela 1 - Composição setorial e taxa de variação do total das exportações dos países selecionados durante a década de 2000 (em \%)

\begin{tabular}{|c|c|c|c|c|c|c|c|c|c|c|c|c|c|c|c|}
\hline & \multicolumn{3}{|c|}{ China } & \multicolumn{3}{|c|}{ Cingapura } & \multicolumn{3}{|c|}{ Coreia do Sul } & \multicolumn{3}{|c|}{ Hong Kong } & \multicolumn{3}{|c|}{ Japão } \\
\hline $\begin{array}{l}\text { Metodologia } \\
\text { de Lall }\end{array}$ & $\begin{array}{l}n \\
0 \\
\vdots \\
8 \\
i\end{array}$ & $\begin{array}{l}\circ \\
\text { bे } \\
\stackrel{\text { ¿े }}{ }\end{array}$ & $\dot{\vec{z}} \stackrel{\varrho}{\varrho}$ & \begin{tabular}{l}
$n$ \\
0 \\
$\vdots$ \\
8 \\
\hdashline
\end{tabular} & 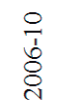 & 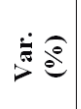 & $\begin{array}{l}n \\
0 \\
\vdots \\
8 \\
0\end{array}$ & $\begin{array}{l}\circ \\
\bar{b} \\
8 \\
8\end{array}$ & 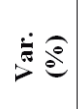 & $\begin{array}{l}n \\
0 \\
o \\
8 \\
0\end{array}$ & $\begin{array}{l}\circ \\
\text { ठे } \\
\stackrel{1}{0}\end{array}$ & 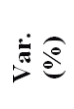 & $\begin{array}{l}n \\
0 \\
\vdots \\
8 \\
8\end{array}$ & $\begin{array}{l}\circ \\
\text { ठे } \\
\stackrel{1}{0}\end{array}$ & $\dot{\bar{\nu}} \circlearrowright$ \\
\hline $\begin{array}{l}\text { Produtos } \\
\text { primários }\end{array}$ & 5,2 & 3,4 & $-34,8$ & 1,9 & 2,0 & 1,1 & 2,4 & 3,0 & 21,6 & 2,0 & 2,4 & 17,5 & 1,6 & 2,5 & 54,4 \\
\hline $\begin{array}{l}\text { Manufaturas } \\
\text { baseadas em } \\
\text { recursos }\end{array}$ & 8,3 & 7,9 & $-4,5$ & 16,6 & 24,4 & 46,9 & 10,7 & 13,4 & 24,6 & 5,0 & 5,3 & 7,5 & 6,6 & 9,1 & 38,8 \\
\hline $\begin{array}{l}\text { Baixa } \\
\text { tecnologia }\end{array}$ & 37,0 & 31,8 & $-14,1$ & 6,8 & 6,7 & $-2,0$ & 15,7 & 11,8 & $-24,7$ & 35,5 & 25,0 & $-29,5$ & 9,4 & 10,5 & 12,1 \\
\hline $\begin{array}{l}\text { Média } \\
\text { tecnologia }\end{array}$ & 19,3 & 21,3 & 10,1 & 15,8 & 16,7 & 5,4 & 34,7 & 38,1 & 9,7 & 19,8 & 18,1 & $-8,3$ & 52,9 & 54,7 & 3,4 \\
\hline $\begin{array}{l}\text { Alta } \\
\text { tecnologia }\end{array}$ & 30,2 & 35,6 & 18,0 & 58,9 & 50,3 & $-14,5$ & 36,4 & 33,7 & $-7,3$ & 37,7 & 49,1 & 30,2 & 29,5 & 23,1 & $-21,6$ \\
\hline
\end{tabular}

Fonte: Elaboração própria a partir de dados da United Nations Commodity Trade Statistics Database (2011).

De acordo com a Tabela 1, verifica-se a elevação da participação dos produtos de "Média Tecnologia" e de "Alta Tecnologia" na composição da pauta de exportação das economias analisadas. Nesses subgrupos, os quais são diretamente o objeto de estudo deste trabalho, destaca-se a participação de Cingapura, país que detém considerável concentração conjunta de sua pauta exportadora nesses dois subgrupos, passando de aproximadamente $73 \%$ para cerca de $66 \%$ no segundo subperíodo. Destaca-se também a Coreia do Sul, país no qual durante todo o período analisado manteve participação constante em torno de $70 \%$ de sua pauta exportadora nesses dois subgrupos.

Com relação aos demais países, verifica-se que suas pautas exportadoras encontram-se essencialmente concentradas nos subgrupos de "Média Tecnologia" e "Alta Tecnologia" durante o período analisado, apesar da queda de participação média relativa do subgrupo "Alta Tecnologia" em Cingapura (14\%), Coreia do Sul (7\%) e Japão (21\%), de 2000 a 2005 para 2006 a 2010, fruto do aumento relativo da participação da economia chinesa nesse subgrupo e também da crise internacional que se aprofundou no segundo subperíodo. ${ }^{5}$

Contudo, cabe chamar a atenção para a diversificação da pauta exportadora chinesa. Como posto, há uma crescente participação dos produtos intensivos em

5 Cabe destacar que apesar do presente trabalho compreender a relevância do processo de transferência produtiva das empresas desses países para a economia chinesa e o impacto que isto gera na composição setorial da China, aqui se discute apenas o demonstrado pelos números, devido à complexidade desse processo e à impossibilidade de tratá-la a fundo neste trabalho e também ao escopo que se propõe o trabalho. 
tecnologia, contudo aqueles produtos com baixo nível de agregação tecnológica, enquadrados sob o grupo de "Baixa Tecnologia", ainda demonstram participação considerável no montante exportado mesmo com a relativa perda de $37 \%$ para aproximadamente $31 \%$.

Como se pode perceber, o montante exportado baseado em produtos com alta intensidade tecnológica, apesar de crescente, ainda se encontra inferior a vários países da amostra. Em outras palavras, apesar da estrutura setorial da pauta exportadora chinesa assemelhar-se àquela do Japão e dos Dragões asiáticos, ainda se concentra nos subgrupos "Produtos Primários", "Manufaturas baseadas em Recursos" e "Baixa Tecnologia", setores esses que representam, em termos médios durante a década de 2000 , aproximadamente $50 \%$ da pauta exportadora, enquanto, nos demais países, esses subgrupos representam em média cerca de 30\% em Cingapura e Coreia do Sul; 40\% em Hong Kong; e apenas 20\% na pauta exportadora do Japão.

Portanto, a economia chinesa ainda não conseguiu criar uma estrutura industrial interligada com a presença de empresas multinacionais voltadas para a produção em mercados intensivos em tecnologia, apesar dos avanços recentes. Assim, como destacado por Nonnemberg (2011, p. 24), "[...] cada vez mais, a China vem também produzindo partes, peças e componentes da cadeia eletrônica. Dessa forma, ela já ultrapassou, em muitos casos, a fase de simples montagem de produtos finais à base de componentes importados".

Mesmo com tais evidências muitos estudos ainda não admitem que tenha havido incorporação significativa de conteúdo tecnológico das exportações da China. Segundo Medeiros (2011), alguns estudos desenvolvidos apontam que ainda se configura uma estrutura de especialização próxima àquela descrita pelo Esquema de Gansos Voadores (EGV). Assim, ainda que a China tenha elevado o grau de sofisticação de sua pauta exportadora, a hierarquia entre esses países não apresentou mudanças relevantes, mantendo-se a economia japonesa como principal fornecedora de produtos intensivos em tecnologia, seguida dos países asiáticos. Tendo isso em vista, cabe destacar que em muitas cadeias produtivas a China ainda não deixou de ser vista apenas como especialista na montagem final de produtos, mesmo com a relevante intensificação das políticas industriais, as quais têm como grande objetivo de longo prazo a maior incorporação de setores industriais intensivos em tecnologia. Entretanto, como pode ser percebido,

[...] a China ainda não atingiu o atual estágio de Coréia, Taiwan e Cingapura no que se refere ao domínio das tecnologias e desenvolvimento de marcas. Por isso mesmo, é surpreendente o seu desempenho tão superior ao desses três países no que se refere ao crescimento das exportações (NONNEMBERG, 2011, p. 24). 
Outro importante trabalho é de Gaulier, Lemoine e Ünal-Kesenci (2006), o qual analisa como o crescimento da China tem alterado a especialização dos outros países asiáticos e influenciado a integração regional, o crescimento da participação dos produtos de alta tecnologia tem sido liderado por multinacionais, sendo direcionado para os seus parceiros comerciais na Ásia. Nesse sentido, a posição da China no comércio de produtos de alta tecnologia reflete, de acordo com os autores, a posição assumida pela economia chinesa na segmentação internacional de processos de produção mais do que seu upgrading de suas capacidades domésticas.

De acordo com esses autores, a maioria significativa dos insumos importados pela China para posterior reexportação advém do leste asiático. Dessa forma, a oferta de bens intermediários para processamento facilita a expansão da economia chinesa em direção a essa região, elevando o comércio da China com aquelas economias. Esse tipo de comércio envolve as firmas do leste asiático, mas também empresas americanas e europeias, as quais operam naquela localidade.

Nesse sentido, vários trabalhos, entre eles Lemoine e Unal-Kesenci (2002) e Gaulier, Lemoine e Ünal-Kesenci (2006), têm apontado a importância do comércio de bens intermediários e a influência da proximidade geográfica na divisão do trabalho regional, os quais exerceriam o papel das vantagens comparativas ricardianas ao longo do processo de produção. Não sendo, portanto, em virtude de maior incorporação de setores intensivos em tecnologia, mas apenas fruto do aumento de produtividade, reflexo da divisão regional do trabalho.

No entanto, não se pode ignorar que a China vem avançando na incorporação da cadeia de valor, conforme aponta a Carta IEDI (2011), baseado em políticas de longo prazo desde a década de 1980 elaborando planos de desenvolvimento científico e tecnológico, sendo estes articulados com as políticas industriais do país. Tal avanço pode ser percebido na Tabela 2, a qual desmembra a pauta importadora dos países analisados. 
Tabela 2 - Composição setorial e taxa de variação do total das importações dos países selecionados durante a década de 2000 (em \%)

\begin{tabular}{|c|c|c|c|c|c|c|c|c|c|c|c|c|c|c|c|}
\hline & \multicolumn{3}{|c|}{ China } & \multicolumn{3}{|c|}{ Cingapura } & \multicolumn{3}{|c|}{ Coreia do Sul } & \multicolumn{3}{|c|}{ Hong Kong } & \multicolumn{3}{|c|}{ Japão } \\
\hline $\begin{array}{c}\text { Metodologia } \\
\text { de Lall }\end{array}$ & 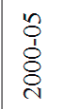 & 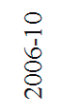 & $\dot{\bar{v}}$ & 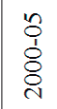 & 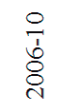 & $\dot{\bar{\sigma}} \widehat{\varrho}$ & 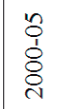 & \begin{tabular}{l}
$\circ$ \\
\multirow{1}{0}{} \\
8 \\
8
\end{tabular} & $\dot{\bar{z}}$ & 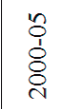 & 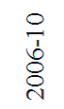 & $\dot{\bar{v}}$ & $\begin{array}{l}n \\
0 \\
\vdots \\
8 \\
\text { N }\end{array}$ & $\begin{array}{l}\circ \\
\text { ठे } \\
\stackrel{1}{0}\end{array}$ & $\dot{\bar{\sigma}}$ \\
\hline & 28.9 & 30.7 & 5.9 & 10.5 & 13.1 & 24.2 & 24.9 & 27.7 & 11.3 & 4.1 & 4.2 & 2.0 & 27.0 & 31.7 & 17.1 \\
\hline $\begin{array}{l}\text { Manufaturas } \\
\text { aseadas em } \\
\text { ecursos }\end{array}$ & 10.8 & 14.2 & 31.1 & 12.7 & 20.4 & 60.5 & 15.5 & 16.9 & 8.9 & 9.3 & 10.2 & 10.2 & 18.1 & 18.1 & -0.3 \\
\hline $\begin{array}{l}\text { Baixa } \\
\text { tecnologia }\end{array}$ & 9.7 & 6.0 & -38.0 & 8.5 & 7.9 & 73 & 10.6 & 12.1 & 14.7 & 27.8 & 20.5 & -26.3 & 15.5 & 14.5 & -6.2 \\
\hline $\begin{array}{l}\text { Média } \\
\text { tecnologia }\end{array}$ & 21.6 & 18.5 & -14.4 & 19.1 & 18.3 & -4.1 & 20.3 & 21.9 & 7.5 & 19.7 & 17.8 & -9.9 & 16.5 & 16.7 & 0.9 \\
\hline $\begin{array}{l}\text { Alta } \\
\text { tecnologia }\end{array}$ & 28.9 & 30.7 & 5.9 & 49.2 & 40.3 & -18.0 & 28.7 & 21.4 & -25.4 & 39.1 & 47.3 & 21.1 & 22.9 & 19.1 & -16.5 \\
\hline
\end{tabular}

Fonte: Elaboração própria a partir de dados da United Nations Commodity Trade Statistics Database (2011).

De acordo com a Tabela 2, verifica-se que não existe um padrão entre os países analisados. Enquanto Cingapura e Hong Kong possuem cerca de $40 \%$ de suas pautas nos produtos de "Alta Tecnologia", países como China, Coreia do Sul e Japão concentram aproximadamente $30 \%$ do total importado em "Produtos Primários", fato este já esperado uma vez que tais países não detêm abundante produção de produtos primários. Com relação aos subgrupos de "Média Tecnologia" e "Alta Tecnologia", foco deste trabalho, os países analisados apresentaram, na média, queda da participação desses componentes no total importado.

No que se refere à economia chinesa, verificou-se redução do total dos produtos de "Média Tecnologia", enquanto houve uma ampliação em cerca $2 \%$ nos total de produtos de "Alta Tecnologia". Cabe salientar que, mesmo com tais resultados, a economia chinesa ainda encontra-se longe dos resultados apresentados pela economia japonesa, a qual apresenta índices inferiores de dependência de importação de produtos mais sofisticados, o que sugere que a economia japonesa alcançou sucesso no processo de incorporação de setores mais intensivos em tecnologia. No entanto, para tornar mais clara a existência ou não da dependência de produtos importados de maior valor agregado, apresenta-se a Tabela 3, a qual demonstra o saldo comercial setorial dos países analisados. 
Tabela 3 - Saldo comercial setorial dos países selecionados durante a década de 2000 (em bilhões de dólares)

\begin{tabular}{|c|c|c|c|c|c|c|c|c|c|c|}
\hline ran & \multicolumn{2}{|c|}{ China } & \multicolumn{2}{|c|}{ Cingapura } & \multicolumn{2}{|c|}{ Coreia do Sul } & \multicolumn{2}{|c|}{ Hong Kong } & \multicolumn{2}{|c|}{ Japão } \\
\hline $\begin{array}{l}\text { Metodologia } \\
\text { de Lall }\end{array}$ & $\begin{array}{l}n \\
0 \\
1 \\
8 \\
8\end{array}$ & 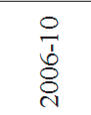 & $\begin{array}{l}n \\
0 \\
1 \\
8 \\
8 \\
i\end{array}$ & 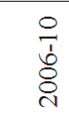 & $\begin{array}{l}n \\
0 \\
1 \\
8 \\
8 \\
\text { 이 }\end{array}$ & $\begin{array}{l}0 \\
\text { bे } \\
8 \\
8\end{array}$ & 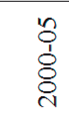 & 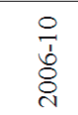 & 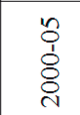 & $\begin{array}{l}0 \\
\stackrel{1}{1} \\
8 \\
8 \\
\text { ㄱ. }\end{array}$ \\
\hline $\begin{array}{l}\text { Produtos } \\
\text { primários }\end{array}$ & $-112,5$ & $-297,6$ & $-12,0$ & $-28,5$ & $-36,1$ & $-77,7$ & $-4,7$ & $-6,8$ & $-86,3$ & $-150,8$ \\
\hline $\begin{array}{l}\text { Manufaturas } \\
\text { baseadas em } \\
\text { recursos }\end{array}$ & $-14,7$ & $-64,4$ & 7,7 & 12,2 & $-4,5$ & $-4,5$ & $-10,2$ & $-18,7$ & $-33,3$ & $-38,0$ \\
\hline $\begin{array}{l}\text { Baixa } \\
\text { tecnologia }\end{array}$ & 105,0 & 318,8 & $-1,6$ & $-2,4$ & 12,0 & 4,1 & 13,4 & 9,6 & $-11,4$ & $-9,8$ \\
\hline $\begin{array}{l}\text { Média } \\
\text { tecnologia }\end{array}$ & $-12,1$ & 53,6 & $-2,6$ & $-2,2$ & 33,6 & 73,2 & $-1,5$ & $-3,3$ & 176,2 & 252,2 \\
\hline Alta tecnologia & $-1,4$ & 93,8 & 18,3 & 31,2 & 24,3 & 56,3 & $-6,2$ & $-6,1$ & 50,9 & 43,5 \\
\hline
\end{tabular}

Fonte: Elaboração própria a partir de dados da United Nations Commodity Trade Statistics Database (2011).

Com poucas exceções, pode-se perceber que a maioria dos países apresenta superávits comerciais nos setores de "Média Tecnologia" e "Alta Tecnologia". Nesses dois grupos de produtos, a China melhorou seus resultados na segunda metade da década de 2000, apresentando tímidos superávits comerciais nessas categorias. No entanto, cabe chamar a atenção que ainda parte considerável dos gigantescos superávits comerciais chineses advém de produtos de "Baixa Tecnologia", em detrimento do Japão o qual detém expressivos superávits nos setores intensivos em tecnologia. Os demais países apresentam déficits razoáveis, em especial em "Produtos Primários".

Com relação a Cingapura, verifica-se que esse país apresenta déficits em produtos de "Média Tecnologia", enquanto houve um considerável aumento no superávit em produtos de "Alta Tecnologia", de cerca de 13 bilhões de dólares. Já a Coreia do Sul, também elevou seu superávit comercial nos setores intensivos em tecnologia, enquanto Hong Kong detém déficits comerciais nesses mesmos setores.

De acordo com a análise das Tabelas 1, 2 e 3, pode-se afirmar que, apesar do esforço despendido, a China ainda não se conforma como o principal polo tecnológico da região. Visando analisar o desempenho de cada país no âmbito do comércio internacional, apresenta-se a Tabela 4, na qual está posta a evolução média do indicador de market-share para os países selecionados durante a década de 2000 . 
Tabela 4 - Market-share dos países selecionados durante a década de 2000 (em \%)

\begin{tabular}{|c|c|c|c|c|c|c|c|c|c|c|}
\hline & \multicolumn{2}{|c|}{ China } & \multicolumn{2}{|c|}{ Cingapura } & \multicolumn{2}{|c|}{ Coreia do Sul } & \multicolumn{2}{|c|}{ Hong Kong } & \multicolumn{2}{|c|}{ Japão } \\
\hline $\begin{array}{l}\text { Metodologia de } \\
\text { Lall }\end{array}$ & \begin{tabular}{l}
$n$ \\
1 \\
8 \\
8 \\
\hdashline
\end{tabular} & $\begin{array}{l}0 \\
\frac{1}{1} \\
\delta \\
8 \\
\text { ㄱ. }\end{array}$ & $\begin{array}{l}n \\
0 \\
8 \\
8 \\
8\end{array}$ & 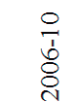 & $\begin{array}{l}n \\
0 \\
1 \\
8 \\
0\end{array}$ & $\begin{array}{l}0 \\
\frac{1}{0} \\
\stackrel{8}{0}\end{array}$ & 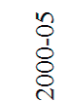 & $\begin{array}{l}0 \\
\text { bे } \\
\stackrel{8}{8}\end{array}$ & 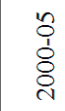 & $\begin{array}{l}0 \\
\frac{1}{0} \\
\stackrel{0}{0} \\
\text { ㄱ. }\end{array}$ \\
\hline $\begin{array}{l}\text { Produtos } \\
\text { primários }\end{array}$ & 2.3 & 2.3 & 0.3 & 0.3 & 0.5 & 0.6 & 0.5 & 0.5 & 0.9 & 0.9 \\
\hline $\begin{array}{l}\text { Manufaturas } \\
\text { baseadas em } \\
\text { recursos }\end{array}$ & 3.1 & 4.8 & 2.4 & 3.2 & 2.0 & 2.4 & 1.1 & 0.9 & 2.8 & 2.8 \\
\hline Baixa tecnologia & 13.3 & 21.2 & 0.9 & 1.0 & 2.8 & 2.3 & 7.2 & 4.6 & 3.9 & 3.6 \\
\hline Média tecnologia & 3.8 & 7.8 & 1.2 & 1.4 & 3.3 & 4.1 & 2.2 & 1.8 & 11.8 & 10.3 \\
\hline Alta tecnologia & 8.6 & 19.0 & 6.0 & 5.9 & 4.8 & 5.3 & 5.7 & 7.2 & 9.1 & 6.3 \\
\hline
\end{tabular}

Fonte: Elaboração própria a partir de dados da United Nations Commodity Trade Statistics Database (2011).

Tomando como referência a Tabela 4, destaca-se a elevada participação média no comércio mundial de manufaturas de alta tecnologia da China, que passa de aproximadamente $8 \%$ no primeiro subperíodo para 19\% de 2006 a 2010, superior ao market-share dos demais países analisados. Com exceção do subgrupo "Produtos Primários", o qual manteve constante o índice médio de market-share, todos os demais apresentaram crescentes participações. Destaca-se, no entanto, que as participações mais representativas da pauta exportadora chinesa encontram-se concentradas nos subgrupos de "Baixa Tecnologia" e "Alta Tecnologia", coerente com a crescente especialização dessa economia nesses subgrupos, conforme já apontou a Tabela 1.

Ainda segundo a Tabela 4, verifica-se que a China detém participação considerável vis-à-vis as demais economias analisadas em setores pouco intensivos em tecnologia, como já demonstrado pela Tabela 1. Enquanto isso, existe um esforço por parte da economia chinesa de elevar sua participação nos setores intensivos em tecnologia apresentando índices superiores àqueles dos Dragões Asiáticos. Já no que se refere à comparação com o Japão, verifica-se que o market-share chinês no subgrupo de "Média Tecnologia" ainda é inferior à economia japonesa. Como apontado na metodologia, os setores considerados de "Média Tecnologia" são o "coração" indústria dos países maduros, pressupondo-se que a indústria chinesa ainda não amadureceu, se comparada com a economia japonesa, apesar do desempenho superior no subgrupo de "Alta Tecnologia".

Cabe destacar também que os próprios indicadores dos Dragões Asiáticos nos subgrupos de "Média Tecnologia" e "Alta Tecnologia" são inferiores àqueles apresentados pela economia japonesa no período analisado, inclusive também aos indicadores da economia chinesa. Nesse sentido, a China vem avançando na sua participação de mercado nos setores intensivos em tecnologia vis-à-vis os Dra- 
gões Asiáticos. No entanto, todos esses países ainda se encontram distantes do que seria tido como mais desenvolvido, aqui representado como o padrão de especialização japonês.

Seguindo o objetivo proposto pelo presente trabalho, cabe destacar os resultados relativos ao subgrupo "Alta Tecnologia" e seus efeitos para o desempenho exportador das economias asiáticas analisadas. Para tanto, desagregaram-se os dados referentes aos setores que compõem esse subgrupo, ao nível de 3 dígitos, segundo a SITC. Os valores são apresentados na Tabela 5, a qual demonstra a evolução da composição setorial do subgrupo de alta tecnologia da pauta exportadora para os países selecionados durante a década de 2000.

Tabela 5 - Composição setorial das exportações das manufaturas de alta tecnologia dos países selecionados durante a década de 2000 (em \%)

\begin{tabular}{|c|c|c|c|c|c|c|c|c|c|c|c|}
\hline & \multicolumn{2}{|c|}{ China } & \multicolumn{2}{|c|}{ Cingapura } & \multicolumn{2}{|c|}{$\begin{array}{l}\text { Coreia do } \\
\text { Sul }\end{array}$} & \multicolumn{2}{|c|}{ Hong Kong } & \multicolumn{2}{|c|}{ Japão } \\
\hline Cod. & Alta Tecnologia & 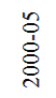 & $\begin{array}{l}\stackrel{0}{1} \\
\stackrel{1}{\circ} \\
\stackrel{0}{0}\end{array}$ & $\begin{array}{l}\text { ᄋ } \\
8 \\
8 \\
8\end{array}$ & $\begin{array}{l}\stackrel{0}{1} \\
\stackrel{1}{0} \\
\stackrel{0}{0}\end{array}$ & 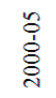 & $\begin{array}{l}\stackrel{0}{1} \\
\stackrel{1}{0} \\
\stackrel{0}{0}\end{array}$ & $\begin{array}{l}\text { o } \\
\stackrel{1}{8} \\
\text { ᄋ }\end{array}$ & $\begin{array}{l}\stackrel{0}{1} \\
\stackrel{1}{0} \\
\stackrel{0}{0}\end{array}$ & 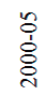 & $\begin{array}{l}\frac{0}{1} \\
\stackrel{1}{0} \\
\stackrel{0}{0}\end{array}$ \\
\hline 524 & Materiais radioativos & 0,4 & 0,3 & 0,0 & 0,1 & 0,1 & 0,1 & 0,1 & 0,1 & 0,3 & 0,5 \\
\hline 541 & Produtos medicinais e farmacêuticos & 2,1 & 1,5 & 0,9 & 1,2 & 0,3 & 0,4 & 0,2 & 0,1 & 0,8 & 0,9 \\
\hline 712 & Equipamentos a vapor, turbinas & 0,0 & 0,2 & 0,0 & 0,1 & 0,1 & 0,1 & 0,0 & 0,0 & 0,7 & 1,0 \\
\hline 716 & Equipamentos elétricos de rotação & 2,8 & 2,2 & 1,3 & 1,1 & 1,0 & 0,9 & 2,5 & 1,5 & 2,4 & 3,4 \\
\hline 718 & Equipamentos de geração de energia & 0,1 & 0,2 & 0,1 & 0,1 & 0,1 & 0,2 & 0,0 & 0,0 & 0,4 & 0,8 \\
\hline 751 & Máquinas de escritório & 2,1 & 3,1 & 0,3 & 1,1 & 0,5 & 0,6 & 1,5 & 0,9 & 1,1 & 1,5 \\
\hline 752 & $\begin{array}{l}\text { Equipamentos de processamento de } \\
\text { dados para carros }\end{array}$ & 25,9 & 27,3 & 20,0 & 7,5 & 13,3 & 6,2 & 7,6 & 6,8 & 8,2 & 3,3 \\
\hline 759 & Outros equipamentos de escritório & 13,3 & 8,6 & 13,9 & 14,1 & 12,5 & 6,6 & 19,8 & 15,7 & 12,0 & 10,9 \\
\hline 761 & Receptores de televisão & 2,7 & 4,0 & 0,7 & 0,4 & 3,5 & 1,6 & 0,8 & 0,6 & 3,1 & 1,3 \\
\hline 764 & Equipamentos de telecomunicações & 23,0 & 25,3 & 9,2 & 9,3 & 28,4 & 31,5 & 23,4 & 28,3 & 11,4 & 11,7 \\
\hline 771 & Máquinas de energia elétrica & 4,7 & 3,5 & 1,2 & 1,1 & 1,2 & 1,7 & 5,7 & 5,1 & 1,7 & 2,1 \\
\hline 774 & Equipamentos de precisão & 0,2 & 0,3 & 0,1 & 0,2 & 0,4 & 0,5 & 0,2 & 0,2 & 1,7 & 2,3 \\
\hline 776 & $\begin{array}{l}\text { Lâmpadas, tubos e válvulas de } \\
\text { cátodo }\end{array}$ & 8,3 & 9,7 & 44,1 & 53,7 & 30,4 & 24,6 & 24,1 & 30,8 & 28,2 & 30,1 \\
\hline 778 & Maquinário elétrico & 8,6 & 6,8 & 4,0 & 3,9 & 4,0 & 6,1 & 6,7 & 5,5 & 12,9 & 14,3 \\
\hline 792 & Aeronaves & 0,5 & 0,3 & 1,2 & 2,7 & 0,6 & 0,6 & 0,2 & 0,1 & 1,1 & 1,8 \\
\hline 871 & Instrumentos de óptica & 2,6 & 5,0 & 0,4 & 0,3 & 2,5 & 17,0 & 2,1 & 1,5 & 2,7 & 3,4 \\
\hline 874 & Instrumentos e aparelhos de medição & 1,4 & 1,4 & 2,1 & 2,7 & 0,8 & 1,2 & 2,2 & 2,1 & 7,6 & 9,6 \\
\hline 881 & Equipamentos fotográficos & 1,2 & 0,1 & 0,4 & 0,3 & 0,2 & 0,1 & 2,8 & 0,5 & 3,5 & 0,9 \\
\hline
\end{tabular}

Fonte: Elaboração própria a partir de dados da United Nations Commodity Trade Statistics Database (2011).

A análise desagregada do subgrupo de "Alta Tecnologia" da China permite perceber que esse país vem aumentando sua participação, sendo que apenas oito setores reduziram suas participações no total exportado, com especial destaque para "Produtos Medicinais e Farmacêuticos" (541), passando de 2\% para 1,5\%; "Maquinário Elétrico" (778), diminuindo sua participação em 2 pontos percentuais; e "Equipamento Fotográfico" (881), que perdeu aproximadamente 1 pon- 
to percentual. Já os demais países vêm apresentando participação crescente na maioria dos setores analisados

De acordo com a Tabela 5, a composição da pauta exportadora do subgrupo de "Alta Tecnologia" é semelhante entre os países analisados, tendo como parâmetro a economia japonesa. Cabe salientar que, na maioria dos setores, a pauta exportadora da China se destaca dos demais países. Nos setores "Equipamentos de Telecomunicações" (764), "Lâmpadas, tubos e válvulas de catodo" (776)" e "Instrumentos e aparelhos de medição" (874), a participação chinesa é inferior a dos demais países, em especial, a dos Dragões Asiáticos. Já no se refere ao setor "Equipamentos de processamento de dados para carro" (752), a China destaca-se, uma vez que seus índices giram em torno de $26 \%$ e a sua participação foi crescente durante a década de 2000, enquanto os demais países ficam aproximadamente em $10 \%$ e suas participações se reduziram no período analisado. Com o fim de aprofundar as considerações feitas, apresenta-se a Tabela 6, na qual consta o indicador de market-share do subgrupo de manufaturas de "Alta Tecnologia" desagregado a 3 dígitos.

Tabela 6 - Market-share setorial das exportações das manufaturas de alta tecnologia dos países selecionados durante a década de 2000 (em \%)

\begin{tabular}{|c|c|c|c|c|c|c|c|c|c|c|c|}
\hline \multirow[b]{2}{*}{ Cod. } & \multirow[b]{2}{*}{ Manufaturas de Alta Tecnologia } & \multicolumn{2}{|c|}{ China } & \multicolumn{2}{|c|}{ Cingapura } & \multicolumn{2}{|c|}{$\begin{array}{l}\text { Coreia do } \\
\text { Sul }\end{array}$} & \multicolumn{2}{|c|}{$\begin{array}{l}\text { Hong } \\
\text { Kong }\end{array}$} & \multicolumn{2}{|c|}{ Japão } \\
\hline & & 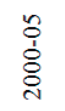 & 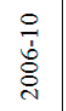 & 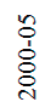 & 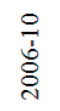 & $\begin{array}{l}n \\
1 \\
8 \\
8 \\
8\end{array}$ & $\begin{array}{l}\circ \\
\frac{1}{8} \\
\stackrel{\circ}{\circ}\end{array}$ & 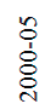 & $\begin{array}{l}\frac{0}{1} \\
\stackrel{\circ}{\circ}\end{array}$ & 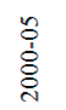 & 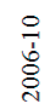 \\
\hline 524 & Materiais radioativos & 10,2 & 12,3 & 0,6 & 0,9 & 1,3 & 1,4 & 2,1 & 1,9 & 7,3 & 7,7 \\
\hline 541 & Produtos medicinais e farmacêuticos & 4,9 & 5,9 & 1,7 & 1,5 & 0,5 & 0,5 & 0,4 & 0,2 & 2,4 & 1,2 \\
\hline 712 & Equipamentos a vapor, turbinas & 1,5 & 10,9 & 0,7 & 2,0 & 1,3 & 1,5 & 0,1 & 0,0 & 29,2 & 23,1 \\
\hline 716 & Equipamentos elétricos de rotação & 8,2 & 13,1 & 2,9 & 2,0 & 1,8 & 1,5 & 5,4 & 3,3 & 8,4 & 6,6 \\
\hline 718 & Equipamentos de Geração de energia & 1,6 & 5,1 & 0,6 & 0,9 & 0,8 & 1,1 & 0,3 & 0,3 & 7,3 & 6,7 \\
\hline 751 & Máquinas de escritório & 19,3 & 35,0 & 2,2 & 3,4 & 2,6 & 2,0 & 8,8 & 3,7 & 11,0 & 5,2 \\
\hline 752 & $\begin{array}{l}\text { Equipamentos de processamento de } \\
\text { dados para carros }\end{array}$ & 16,6 & 39,9 & 8,3 & 3,4 & 4,4 & 2,4 & 3,0 & 3,7 & 5,4 & 1,6 \\
\hline 759 & Outros equipamentos de escritório & 10,5 & 18,5 & 7,5 & 9,5 & 5,5 & 3,8 & 10,4 & 12,8 & 9,9 & 7,9 \\
\hline 761 & Receptores de televisão & 9,0 & 19,7 & 1,7 & 0,7 & 6,4 & 2,0 & 1,8 & 1,1 & 10,8 & 2,2 \\
\hline 764 & Equipamentos de telecomunicações & 11,5 & 26,3 & 3,2 & 3,0 & 8,1 & 9,4 & 7,8 & 11,1 & 6,1 & 4,0 \\
\hline 771 & Máquinas de energia elétrica & 14,6 & 21,8 & 2,8 & 2,1 & 2,4 & 3,2 & 12,5 & 12,0 & 6,2 & 4,3 \\
\hline 774 & Equipamentos de precisão & 1,5 & 4,1 & 0,4 & 0,9 & 1,4 & 1,7 & 0,9 & 0,9 & 11,7 & 9,5 \\
\hline 776 & $\begin{array}{l}\text { Lâmpadas, tubos e válvulas de } \\
\text { cátodo }\end{array}$ & 3,7 & 10,3 & 13,6 & 17,6 & 7,5 & 7,5 & 7,1 & 12,4 & 13,1 & 10,6 \\
\hline 778 & Maquinário elétrico & 9,1 & 17,3 & 3,2 & 3,1 & 2,7 & 4,0 & 5,1 & 5,2 & 15,7 & 12,1 \\
\hline 792 & Aeronaves & 0,5 & 0,8 & 0,9 & 2,3 & 0,4 & 0,4 & 0,2 & 0,2 & 1,3 & 1,6 \\
\hline 871 & Instrumentos de óptica & 19,3 & 35,6 & 2,2 & 0,7 & 9,0 & 36,7 & 10,5 & 4,1 & 21,8 & 8,0 \\
\hline 874 & Instrumentos e aparelhos de medição & 1,9 & 4,6 & 2,1 & 2,6 & 0,7 & 1,1 & 2,1 & 2,4 & 11,5 & 10,0 \\
\hline 881 & Equipamentos fotográficos & 6,5 & 7,6 & 2,2 & 5,2 & 0,9 & 0,9 & 12,7 & 9,8 & 27,7 & 11,7 \\
\hline
\end{tabular}

Fonte: Elaboração própria a partir de dados da United Nations Commodity Trade Statistics Database (2011). 
Como se pode perceber, os índice de market-share da economia chinesa são crescentes vis-à-vis a participação mundial em todos os setores que compõem o subgrupo de "Alta Tecnologia", com destaque para o aumento de participação dos setores "Produtos Medicinais e Farmacêuticos" (541), que passou de 5\% para 6\%; "Equipamento de processamento de dados para carros" (752), que passou de $16 \%$ para 40\%; "Equipamentos de telecomunicações" (764), que se elevou de 11\% para 26\%; e, por fim, "Instrumentos de Óptica" (871), que passou de 19\% para aproximadamente $36 \%$.

Verifica-se que a participação chinesa demonstra-se superior à das demais economias analisadas, inclusive à do Japão. Cabe destacar que apenas no setor "Equipamentos a vapor e turbinas" (712), o Japão detém a participação média de $26 \%$ ao longo da década de 2000, enquanto a participação da economia chinesa, apesar de ter elevado de 1\% para 10\%, ainda se encontra inferior em comparação com o país desenvolvido, no caso, o Japão. Os Dragões Asiáticos, ainda que se constate a elevação de seus indicadores de market-share no subgrupo "Alta Tecnologia”, apresentam índices insignificantes em comparação com a China e o Japão.

Diante desses resultados, verifica-se que a China vem se destacando na exportação de produtos intensivos em tecnologia, face às economias mais avançadas do continente asiático no que se refere à incorporação de setores industriais de tecnologia de ponta, corroborando o apontado por Rodrik (2006), o qual afirma que a experiência chinesa vem demonstrando que não importa a quantidade exportada, mas sim a qualidade. Contudo, apesar dos resultados positivos, a simples análise dos dados desagregados da pauta exportadora ainda é insuficiente, dado que os resultados analisados podem estar de alguma forma sendo arbitrários e criando assim a chamada "ilusão estatística".

Nesse sentido, dado a prerrogativa deste trabalho de analisar qual o desempenho das exportações baseadas em setores de alta tecnologia da China vis-à-vis às economias asiáticas avançadas no processo de upgrading tecnológico, tais como o Japão e os Dragões Asiáticos durante a década de 2000, construiu-se um índice de intensidade tecnológica, o qual será apresentado na seção seguinte. Assim, a construção desse indicador de intensidade tecnológica encontra-se compatível com o fim de criar medidas mais coerentes de mensurar a capacidade de incorporar a produção de produtos intensivos em tecnologia e não apenas especializar-se na montagem final e comercialização desses produtos.

\section{5 Índice de Intensidade Tecnológica das Exportações: Metodologia e Análise dos Dados}

Apesar de válido, o simples agrupamento das exportações segundo categorias de intensidade tecnológica (IT) não é em si mesmo relevante, dado que não 
se aprofunda no modus operandi daquela economia, ou seja, não se torna claro se os processos produtivos são relativamente compatíveis, conforme a discussão da seção 4. Diante dessa prerrogativa, o presente trabalho optou pelo cálculo de um índice de intensidade tecnológica, o qual pode ser concebido pela média de intensidade tecnológica das exportações, atribuindo diferentes pesos às categorias da Metodologia de Lall (2000a).

O índice de intensidade tecnológica das exportações foi desenvolvido por Nonnemberg (2011), em seu trabalho que analisa a intensidade tecnológica da pauta exportadora dos países asiáticos vis-à-vis a pauta exportadora dos países selecionados da América Latina. Nesse sentido, o autor aponta as lacunas da utilização das classificações por categoria tecnológica das exportações, criando assim um índice único, por meio da atribuição de pesos crescentes às categorias mais intensas em tecnologia, formando assim um índice de concentração tecnológica das exportações. O autor, em seu trabalho, aplicou esse índice para o período 1983-2008 à classificação da United Nations Conference on Trade and Development (UNCTAD) (2002), com base nos dados do United Nations Commodity Trade Statistics Database (2011). Diante disso, construiu o índice de intensidade tecnológica das exportações baseado no índice de concentração de Herfindahl-Hirschman da seguinte forma:

$$
\mathrm{IT}=\sum_{i=0}^{n} 2^{\mathrm{Z}}
$$

sendo,Z o peso atribuído a cada categoria tecnológica.

Assim, o presente trabalho se baseia no índice proposto por Nonnemberg (2011), aplicando-o de maneira diversa, uma vez que o autor utilizou-se de uma metodologia diferente para a desagregação das exportações, como também ponderou os subgrupos com diferentes pesos dos adotados no presente trabalho. Dessa forma, neste trabalho, ao se adotar a metodologia de Lall (2000a), atribuíram-se os seguintes pesos para cada categoria: produtos primários $Z=0$; manufaturas baseadas em recursos $Z=1$; manufaturas com baixa tecnologia $Z=2$; manufaturas com média tecnologia $Z=3$; e, por fim, manufaturas de alta tecnologia $Z=4$.

Assim sendo, o país em que suas exportações sejam concentradas em produtos primários terá o seu IT igual a 1, e o país que exporte principalmente manufaturas de alta tecnologia terá o seu IT igual a 16. Nesse sentido, o índice proposto neste trabalho varia de 1 a 16, ao contrário do índice proposto por Nonnemberg (2011), que varia de 1 a 32. Quanto mais próximo a 16, mais intensiva em conteúdo tecnológico será a pauta exportadora. Cabe, no entanto, salientar que a tal índice não podem ser atribuídas propriedades cardinais, servindo ele apenas como ordenamento. O país que tenha suas exportações classificadas como 8 não possui 
a metade da intensidade tecnológica do que aquele que possui IT igual a 16, mas meramente um está na frente do outro, tecnologicamente falando.

Assim como Nonnemberg (2011), o trabalho de Lall, Weiss e Zhang (2006) também apresenta a insatisfação com as propostas existentes para a classificação do comércio internacional. Com isso, os autores também propõem uma nova classificação considerada mais sofisticada, a qual levaria em consideração as características do produto, mas estas seriam ponderadas pela renda média dos países exportadores.

De acordo com Lall, Weiss e Zhang (2006), o produto é mais sofisticado quanto maior a renda média do país exportador. Assim sendo, na ausência de intervenções comerciais, os produtos exportados pelos países mais ricos possuem características que permitem que tenham competitividade no mercado mundial, a qual é de certa forma ofuscada pelos altos salários. As características dos produtos ressaltadas pelos autores, além de fatores técnicos, incluindo a tecnologia, também consideram questões econômicas, como localização e mercado, e fatores políticos, como barreiras tarifárias e subsídios, entre outros.

Diante disso, levando em consideração as características de cada produto, os autores montaram um índice único de sofisticação tecnológica, utilizando dados do total exportado por cada economia e seu nível médio de renda. Assim, os índices foram calculados para cada produto individual ponderado pela renda média do país exportador, sendo o peso o market-share de cada país nas exportações mundiais. Posteriormente, os índices foram normalizados em uma escala de 0 a 100. A maior vantagem do índice proposto pelos autores é a simplicidade da informação contida em um único indicador. Os autores calcularam os índices de sofisticação para aproximadamente 237 setores SITC a 3 dígitos e cerca de 766 setores SITC a 4 dígitos para o período de 1990 a 2000.

Diante disso, sabe-se que qualquer classificação é dotada de arbitrariedade, sendo que essa metodologia não se encontra excluída. Mesmo com isso, o índice proposto por Nonnemberg (2011) é elucidativo no sentido de proporcionar uma métrica mais adequada para a comparação das pautas exportadoras com relação à intensidade tecnológica dos países analisados. Mediante essa discussão, na Tabela 7, apresentam-se os índices construídos para os países asiáticos da amostra para o período de 2000 a 2010, baseados nos dados da United Nations Commodity Trade Statistics Database (2011). 
Tabela 7 - Índice de Intensidade Tecnológica para os países selecionados para os anos 2000

\begin{tabular}{c|ccccc}
\hline País/Ano & China & Cingapura & $\begin{array}{c}\text { Coreia do } \\
\text { Sul }\end{array}$ & Hong Kong & Japão \\
\hline 2000 & 7,26 & 11,91 & 9,43 & 8,48 & 9,92 \\
2001 & 7,51 & 11,67 & 9,02 & 8,67 & 9,63 \\
2002 & 7,86 & 11,54 & 9,43 & 8,97 & 9,45 \\
2003 & 8,34 & 11,06 & 9,64 & 9,29 & 9,41 \\
2004 & 8,68 & 10,96 & 9,71 & 9,60 & 9,35 \\
2005 & 8,78 & 10,70 & 9,57 & 9,94 & 9,12 \\
2006 & 8,81 & 10,67 & 9,42 & 10,16 & 9,00 \\
2007 & 8,83 & 10,39 & 9,31 & 10,22 & 8,78 \\
2008 & 8,72 & 9,75 & 8,87 & 10,33 & 8,55 \\
2009 & 8,96 & 10,00 & 9,25 & 10,61 & 8,63 \\
2010 & 9,01 & 10,01 & 9,21 & 10,88 & 8,57 \\
\hline
\end{tabular}

\begin{tabular}{|c|c|}
\hline \multicolumn{2}{|c|}{ Legenda } \\
\hline 1 até 2 & \\
\hline 2 até 4 & \\
\hline 4 até 8 & \\
\hline 8 até 16 & \\
\hline
\end{tabular}

Fonte: Elaboração própria a partir de dados da United Nations Commodity Trade Statistics Database (2011).

Utilizando da formatação condicional, pode-se verificar que Cingapura, Coreia do Sul e Hong Kong são os países apresentam os maiores Índices de Intensidade Tecnológica durante a década analisada, apesar de se notar o crescimento constante da intensidade média de todos os países asiáticos analisados. Cingapura é o país que apresenta os maiores índices, mesmo com a relativa queda em 2008 , em função da crise do subprime. A Coreia do Sul apresenta um índice de tecnologia constante ao longo da década, mesmo com a falta do dado de 2010 e também da queda em 2008, em consequência da crise do subprime.

Hong Kong, mesmo com a elevação de suas exportações intensivas em tecnologia, apresenta desempenho mediano e crescente ao longo da década, mas inferior a outros países como a Coreia do Sul e Cingapura. Contudo, seu fraco desempenho encontra-se relacionado ao fato de que, desde o começo dos anos 1990, Hong Kong vem transformando sua economia concentrada no setor de serviços, deslocando suas atividades industriais para a China continental (NONNEMBERG, 2011).

O Japão, como já apontado, vem perdendo a importância no cenário global e com a transferência de suas principais empresas para os outros países apresenta redução no seu índice de tecnologia ao longo da década. No que tange à China, corrobora-se o já apontado, de que tal economia venha, devido à intensidade das políticas industriais (principalmente aquelas voltadas para estimular as atividades inovativas e a aquisição de conhecimento externo), caminhando rumo à incorporação de setores intensivos em tecnologia. Mesmo que seu desempenho seja 
relativamente inferior ao dos outros países asiáticos, inclusive ao do Japão, que vem reduzindo seus índices de tecnologia.

Nesse sentido, apesar da relativa incorporação de setores intensivos em tecnologia, a economia chinesa ainda não apresenta o mesmo nível de upgrading tecnológico que as economias asiáticas desenvolvidas. Assim, como já apontado por Kumar e Siddharthan (1994), a incorporação de setores intensivos em tecnologia vai além da capacidade imitativa do país, sendo necessários pesados investimentos na real incorporação de capacitações internas, o que demanda políticas industriais ativas. Por isso, mesmo com o avanço recentes da economia chinesa rumo à incorporação dessas capacitações, o que pode ser demonstrado pelos dados, ainda não se compara com as economias que promoveram aprimoramento tecnológico, uma vez que são procedimentos de longo prazo e independentes da capacidade imitativa ou apenas da realização da montagem final e comercialização dos produtos intensivos em tecnologia.

\section{Considerações Finais}

O crescimento dos países asiáticos, com exceção do Japão, foi na sua maioria guiado pelo esforço exportador, montando na Ásia uma estrutura complexa de divisão regional do trabalho voltado, sobretudo, para atender aos mercados dos países desenvolvidos, tais como Estados Unidos e Europa. Houve então a necessidade de incorporação de setores intensivos em tecnologia para que esses países pudessem se destacar nos mercados dos países desenvolvidos. Nesse sentido, há relevância na construção de capacitações tecnológicas que permitissem o upgrading tecnológico, uma vez que os países asiáticos que avançaram na escala tecnológica absorveram inovações dos países desenvolvidos.

Diante disso, baseado na metodologia de Lall (2000a) verificou-se que os países analisados possuem importantes participações de mercado no subgrupo "Alta Tecnologia", especialmente a China, a qual apresentou índices de market-share superiores àquelas economias que já avançaram na incorporação de conteúdo tecnológico. Apesar disso, a pauta exportadora ainda se concentra no subgrupo "Baixa Tecnologia", ainda que a participação do mesmo venha perdendo significância. Nesse sentido, torna-se importante para o objetivo do presente trabalho desagregar exportações desse subgrupo com o fim de analisar o desempenho da pauta exportadora chinesa vis-à-vis o Japão e os Dragões Asiáticos no período analisado.

Mediante esse procedimento, verificou-se que a estrutura da composição da pauta exportadora chinesa do subgrupo "Alta Tecnologia" vem se assemelhando àquela apresentada pelos demais países analisados. Ademais, os indicadores de market-share da China demonstram-se superiores aos apresentados pelos demais 
países, o que torna, apesar de elucidativo, pouco conclusivo em relação à real incorporação de conteúdo tecnológico das exportações chinesas comparadas com os países avaliados.

Então, diante da necessidade de demonstrar a verdadeira incorporação de conteúdo tecnológico da pauta exportadora da China, este trabalho optou pela construção de um índice de intensidade tecnológica baseado no trabalho de Nonnemberg (2011). O índice de intensidade tecnológico permite sintetizar por meio de um único indicador a intensidade média das exportações dos países analisados por meio da atribuição de pesos mais expressivos para as exportações de maior valor agregado, com o fim de assim permitir uma comparação homogênea entre os países.

Com isso, verificou-se que, apesar dos esforços recentes da economia chinesa na ampliação de sua participação no comércio internacional em setores intensivos em tecnologia, o índice médio de intensidade tecnológica ainda é inferior aos demais países analisados. Os índices de intensidade tecnológica mais representativos foram os de Cingapura, Coreia do Sul e Hong Kong. Seguindo esses países, destaca-se o índice da economia japonesa, que apesar de declinante ao longo da década de 2000, ainda é superior àquele apresentado pela China, sendo isso fruto da transferência das indústrias mais dinâmicas japonesas para outros países da região, atraídas, sobretudo, pelo diferencial de custo de mão de obra e incentivos fiscais.

Tendo isso em vista, apesar dos esforços da China na real incorporação de setores intensivos em tecnologia, ainda não se completou o processo de upgrading tecnológico, o que corrobora a hipótese levantada por este trabalho. Sendo assim, fazem-se necessários investimentos de longo prazo no desenvolvimento de capacitações tecnológicas mediante políticas ativas de incentivo à inovação, dado que, em setores intensivos em tecnologia, a capacidade imitativa é limitada, sem efeitos relevantes para o processo de aprimoramento tecnológico dos países em desenvolvimento.

\section{Referências}

ARBIX, G.; SALERNO, M.; DE NEGRI, J. A. O impacto da internacionalização com foco na inovação tecnológica sobre as exportações das firmas brasileiras. Revista de Ciências Sociais, Rio de Janeiro, v. 48, n. 1, p. 395-442, 2005.

CIMOLI, M. Technological gaps and institucional asymetries in a North-South model with a continuum of goods. Metroeconomica, v. 39, p. 245-274, 1988.

COHEN, W. M.; LEVINTHAL, D. A. Innovation and learning: the two faces of R\&D. The Economic Journal, v. 99, n. 397, p. 569-596, Sept. 1989. 
CONFERÊNCIA DAS NAÇÕES UNIDAS PARA O COMÉRCIO E O DESENVOLVIMENTO. Fortalecendo a participação dos países em desenvolvimento nos setores novos e dinâmicos do comércio mundial: tendências, questões e políticas. São Paulo: United Nations, maio 2004. (Texto para discussão, n. 396).

DE NEGRI, F. Determinantes da capacidade de absorção das firmas brasileiras: qual a influencia do perfil da mão-de-obra? In: ENCONTRO NACIONAL DE ECONOMIA DA ANPEC, 34., 2006, Salvador. Anais eletrônicos... 2006. Disponível em: < http://www.anpec. org.br/encontro2006/artigos/A06A100.pdf> . Acesso em: 14 out. 2011.

Inovação tecnológica e exportação das firmas brasileiras. In: ENCONTRO NACIONAL DE ECONOMIA DA ANPEC, 33., 2005, Natal. Anais eletrônicos... Natal: Anpec, 2005. Disponível em: <http://www.anpec.org.br/encontro2005/artigos/A05A100.pdf>. Acesso em: 18 out. 2011.

DOSI, G. Mudança técnica e transformação industrial: a teoria e uma aplicação à indústria dos semicondutores. Campinas: Editora da Unicamp, 2006.

DOSI, G.; PAVITT, K.; SOETE, L. The economics of technological change and international trade. Brighton: Wheatshaf, 1990.

FIGUEIREDO, P. N. Aprendizagem tecnológica e inovação industrial em economias emergentes: uma breve contribuição para o desenho e implementação de estudos empíricos e estratégias no Brasil. Revista Brasileira de Inovação, v. 3, n. 2, p. 323-361, 2004.

GAULIER, G.; LEMOINE, F.; ÜNAL-KESENCI, D. China's emergence and the reorganisation of trade flows in Asia. Paris: CEPII, Mar. 2006. (Working Paper. 2006-5). Disponível em: <http:// www.cepii.fr/anglaisgraph/workpap/pdf/2006/wp06-05.pdf> . Acesso em: 12 set. 2011.

GUIMARÃES, E. P. Padrão de comércio entre Brasil e Índia, China e alguns países do sudeste asiático. Economia Contemporânea, v. 3, n. 2, p. 125-166, 1999.

HOLLAND, M.; XAVIER, C. L. Dinâmica e competitividade setorial das exportações brasileiras: uma análise de painel para o período recente. Revista Economia e Sociedade, Campinas, v. 14, n. 1 (24), p. 85-108, jan./jun. 2005.

KUMAR, N.; SIDDARTHAN, N. S. Technology, firm size and export behaviour in developing countries: the case of Indian enterprises. The Journal of Development Studies, v. 31, n. 2, p. 289-309, 1994.

KRUGMAN, P. A Model of innovation, technology transfer, and the world distribution of income. Journal of Political Economy, v. 87, n. 2, p. 253-266, 1979.

LALL, S. Export performance, technological upgrading and FDI strategies in the Asian NIEs with special reference to Singapore. 2000a Disponível em: < http://www.eclac.cl/ publicaciones/xml/4/5634/lcl1421i.pdf > . Acesso em: 18 out. 2011.

. The technological structure and performance of developing country manufactured exports, 1985/1998. Oxford Development Studies, v. 28, n. 3, p. 1-39, 2000 b.

LALL, S.; WEISS, J.; ZHANG, J. The "sophistication" of exports: a new trade measure. World Development, v. 34, n. 2, p. 222-237, 2006. 
LAURSEN, K. A new Schumpterian perspective on the determinants and effects of international specialization. Aalborg: Druik/IKE Group, 1998. University Phd Thesis.

LEÃO, R. P. F. A articulação produtiva asiática e os efeitos da emergência chinesa. In: LEÃO, R. P. F.; PINTO; E.C.; ACIOLY, L. (Org.). A China na nova configuração global: impactos políticos e econômicos. Brasília: IPEA, cap. 3, p. 115-164, 2011.

LEMOINE, F.; ÜNAL-KESENCI, D. China in the international segmentation of production processes. Paris: CEPII, 2002. (Working Paper). Disponível em: < http://www.cepii.fr/ anglaisgraph/workpap/pdf/2002/wp02-02.pdf> . Acesso em: 12 set. 2011.

MARKWALD, R. Intensidade tecnológica e dinamismo das exportações brasileiras. Revista Brasileira de Comércio Exterior, Rio de Janeiro, v. 8, n. 79, abr.jun. 2004.

MEDEIROS, C. A. A China como um duplo pólo na economia mundial e a recentralização da economia asiática. Revista de Economia Política, v. 26, n. 3(103), p. 381-400, 2006.

. A dinâmica da integração produtiva asiática e os desafios à integração produtiva no Mercosul. Análise Econômica, Porto Alegre, v. 29, n. 55, p. 7-32, 2011.

NONNEMBERG, M. J. B. Exportações e inovação: uma análise para America Latina e SulSudeste da Ásia. Rio de Janeiro: Ipea, fev. 2011. (Texto para discussão, n. 1579). Disponível em: <http://www.iadb.org/intal/intalcdi/PE/2011/07813.pdf>. Acesso em: 5 out. 2011.

PAVITT, K. Sectoral patterns of the technical change: towards a taxonomy and a theory. Research Policy, v. 13, n. 6, p. 343-373, Dec. 1984.

POSNER, M. V. International trade and technical change. Oxford Economic Papers, v. 13, n. 3, p. 323-341, 1961.

RODRIK, D. What's so special about China's exports? Cambridge, Massachusetts: National Bureau of Economic Research, 2006. (NBER Working Paper, n. 11.947).

VERNON, R. Investimento externo e comércio internacional no ciclo do produto. In: SAVASINI, J. A. A.; MALAN, P. S.; BAER, W. (Org.). Economia internacional. São Paulo: Saraiva, 1966.

XAVIER, C. L.; CUNHA, S. F.; AVELLAR, A. P. M. Desempenho das exportações da indústria intensiva em P\&D: comparação entre o Brasil e países selecionados no período de 19942005. Revista Brasileira de Inovação, Rio de Janeiro, v. 7, n. 2, p. 409-443, 2008

UNITED NATIONS CONFERENCE ON TRADE AND DEVELOPMENT (UNCTAD). World investment report. New York and Geneva: United Nations, 2002

UNITED NATIONS COMMODITY TRADE STATISTICS DATABASE. 2011. Disponível em: <http://comtrade.un.org/db/>. Acesso em: 20 out. 2011.

WIGNARAJA, G. Innovation, learning, and exporting in China: does R\&D or a technology index matter? Journal of Asian Economics, v. 23, n. 3, p. 224-233, 2011.

Recebido em: 10/06/2013. Aceito em: 20/06/2014. 